\title{
Anti-lymphangiogenic properties of mTOR inhibitors in head and neck squamous cell carcinoma experimental models
}

\author{
Oleksandr Ekshyyan ${ }^{1,2}$, Tara N Moore-Medlin 1,2, Matthew C Raley ${ }^{1}$, Kunal Sonavane ${ }^{1,2}$, Xiaohua Rong ${ }^{1,2}$,
} Michael A Brodt ${ }^{1}$, Fleurette Abreo ${ }^{3}$, Jonathan Steven Alexander ${ }^{4}$ and Cherie-Ann O Nathan ${ }^{1,2^{*}}$

\begin{abstract}
Background: Tumor dissemination to cervical lymph nodes via lymphatics represents the first step in the metastasis of head and neck squamous cell carcinoma (HNSCC) and is the most significant predictor of tumor recurrence decreasing survival by 50\%. The lymphatic suppressing properties of mTOR inhibitors are not yet well understood.

Methods: Lymphatic inhibiting effects of rapamycin were evaluated in vitro using two lymphatic endothelial cell (LEC) lines. An orthotopic mouse model of HNSCC (OSC-19 cells) was used to evaluate anti-lymphangiogenic effects of rapamycin in vivo. The incidence of cervical lymph node metastases, numbers of tumor-free lymphatic vessels and those invaded by tumor cells in mouse lingual tissue, and expression of pro-lymphangiogenic markers were assessed.

Results: Rapamycin significantly decreased lymphatic vascular density $(p=0.027)$, reduced the fraction of lymphatic vessels invaded by tumor cells in tongue tissue $(p=0.013)$ and decreased metastasis-positive lymph nodes $(p=0.04)$. Rapamycin also significantly attenuated the extent of metastatic tumor cell spread within lymph nodes $(p<0.0001)$. We found that rapamycin significantly reduced LEC proliferation and was correlated with decreased VEGFR-3 expression in both LEC, and in some HNSCC cell lines.

Conclusions: The results of this study demonstrate anti-lymphangiogenic properties of mTOR inhibitors in HNSCC. mTOR inhibitors suppress autocrine and paracrine growth stimulation of tumor and lymphatic endothelial cells by impairing VEGF-CNEGFR-3 axis and release of soluble VEGFR-2. In a murine HNSCC orthotopic model rapamycin significantly suppressed lymphovascular invasion, decreased cervical lymph node metastasis and delayed the spread of metastatic tumor cells within the lymph nodes.
\end{abstract}

Keywords: Head and neck squamous cell carcinoma, Rapamycin, mTOR inhibitors, mTOR, VEGFR-3, VEGFR-2, Lymph node metastasis

\section{Background}

Despite advances in treatment options, there have been no significant improvements in 5-year survival rates of head and neck squamous cell carcinoma (HNSCC) patients in the past four decades. While the 1-year survival rate is $81 \%$, the 5 -year survival rate remains at $\sim 45 \%$ for

\footnotetext{
* Correspondence: cnatha@lsuhsc.edu

'Department of Otolaryngology/Head and Neck Surgery, Louisiana State University Health Sciences Center, Shreveport, LA, USA

${ }^{2}$ Feist-Weiller Cancer Center, LSUHSC, Shreveport, LA, USA

Full list of author information is available at the end of the article
}

all stages of oral cancer [1]. Metastasis to regional lymph nodes occurs in $30-40 \%$ of HNSCC cases [2], and is associated with poor prognosis and low survival $[2,3]$. Lymphatogenous spread of cancer cells is a significant problem in HNSCC reflecting the rich lymphatic supply in the head and neck. High risk features, such as lymphovascular invasion and extracapsular spread significantly increase the risk of both local recurrence, and distant metastasis. Consequently postoperative adjuvant chemoradiotherapy is recommended to decrease recurrence rates [4]. De Carvalho in a prospective analysis of

\section{Biomed Central}


170 cases of previously untreated patients with laryngeal or hypopharyngeal squamous cell carcinoma found that macroscopic extracapsular tumor spread increased the risk of recurrence 3.5-fold compared with patients with no evidence of metastasis at their initial diagnosis, or patients in whom the tumor was confined to the lymph node [5]. In another study, patients with extracapsular nodal spread had significantly higher rates of recurrent disease and distant metastasis [6].

Tumor cell spread to regional lymph nodes through lymphatic vessels is known to be one of the worst prognostic factors, decreasing survival by $50 \%$. Formation of new tumor-associated lymphatic vessels through lymphangiogenesis plays an active role in the initiation and progression of metastatic disease spread as demonstrated by the significant correlation between intratumoral lymphatic vascular density and lymph node metastasis.

HNSCC is characterized by persistent activation of the Akt/mTOR pathway that triggers a cascade of molecular events central to carcinogenesis including cancer cell survival, cell cycle progression, proliferation, transcription and translation, angiogenesis, invasion, and metastasis $[7,8]$. The Akt/mTOR pathway is a fundamental coordinator of several signaling pathways related to cell growth and division, and mTOR inhibitors effectively reduce proliferation in cells with constitutively upregulated Akt/mTOR signaling. The mammalian target of rapamycin (mTOR) signaling pathway is dysregulated in nearly all (99\%) cases of HNSCC [9]. mTOR inhibitors depress translation of several mRNAs specifically required for tumor cell cycle progression, proliferation, and angiogenesis suppressing oncogenesis [10-15]. Because these pathways are commonly dysregulated in cancer, mTOR represents an attractive anti-tumor target. The mTOR inhibitor rapamycin (sirolimus) was approved by the FDA in 1999 to prevent renal transplant rejection [16] and is a clinically approved immunosuppressive agent with promising anti-tumor properties. Chronic use of rapamycin shows a good safety profile in renal transplantion $[17,18]$ and is well tolerated with only mild and usually reversible side effects which include herpes simplex lesions, acne-like and maculopapular rash, and nail disorders. Dose-limiting toxicities consist of mucositis/stomatitis, asthenia, thrombocytopenia and hyperlipidemia [19].

Although the role of mTOR inhibitors is well established in renal cell carcinoma and recent phase 1 and 2 studies in solid tumors hold promise, their antilymphatic properties are not well characterized. Previously in collaboration with Dr. Silvio Gutkind's group (Oral and Pharyngeal Cancer Branch, National Institute of Dental Research, NIH) using an orthotopic model of HNSCC generated by injection of UMSCC2 cells into the tongue of SCID/NOD mice we demonstrated significant inhibition of tumor growth, decreased lymphatic microvessel density and a decrease in the number of invaded lymph nodes after rapamycin and RAD001 treatment [20]. In the current study we expand the analysis of the anti-lymphatic properties of rapamycin by using an orthotopic murine model of HNSCC generated by injection of highly metastatic OSC-19 cells. Here we investigated the molecular mechanisms of rapalogue anti-lymphatic action and related anti-tumor effects.

\section{Methods}

\section{Evaluation of the anti-lymphangiogenic effects of} rapamycin in a regional metastasis model

All animal studies were carried out according to the protocol approved by the Louisiana State University Health Sciences Center Institutional Animal Care and Use Committee, in compliance with the Committee guidelines. Severe combined immunodeficient (SCID) male mice, 4 to 6 weeks of age (Charles River Laboratories, Wilmington, Massachusetts), were housed in a barrier facility and maintained on a normal diet ad libitum.

$2 \times 10^{5}$ OSC- 19 cells, a highly invasive and metastasisprone oral squamous carcinoma cell line, were injected into the basolateral region of the tongues of SCID mice. The mice were randomized into two groups ( 28 control mice and 25 rapamycin-treated mice ). 5 days after cell injections mice were given daily IP injections of vehicle (4\% DMSO, $5.2 \%$ Tween 80 , and $5.2 \%$ polyethylene glycol 400) or rapamycin at a dose of $5 \mathrm{mg} / \mathrm{kg}$. 21 days after injection of OSC-19 cells mice were sacrificed. Lingual tissue and cervical lymph node samples were harvested. Mouse tongues were bisected and consecutive samples of lingual tissue and cervical lymph nodes were fixed in $10 \%$ neutral buffered formalin for 24 hours, processed and embedded in paraffin. Lingual tissue sections were stained with hematoxylin and eosin (H\&E) and crosssectional area of xenograft tumors was measured using Image-J software (NIH; Windows version). Cervical lymph node samples were examined microscopically by a pathologist using H\&E and cytokeratin staining to determine the cervical lymph node metastasis incidence. The number of tumor-free lymphatic vessels and those invaded by tumor cells in mouse tongues was assessed by our pathologist using LYVE-1 (a lymphatic-specific biomarker) immunohistochemical staining (R\&D Systems, Minneapolis, MN). Lymphatic vessels invaded by tumor cells were defined as those with the presence of tumor cells in the endothelium-lined space (i.e lymphovascular invasion). Blood microvascular density was assessed after immunohistochemical staining with CD31 (PECAM-1; Santa Cruz Biotechnology, Santa Cruz, CA). Individual microvessels were counted using a $\times 400$ field ( $\times 40$ objective lens and $\times 10$ ocular lens). At least three random fields within the tumor area were viewed and counted at $\times 400$ magnification. Results were expressed as the average number of 
microvessels per field. Unpaired t test with Welch correction was used to evaluate the differences between treatment groups.

\section{Cell Lines}

HMEC-1A cells are a human lymphatic endothelial cell line that was subcloned [21] from HMEC-1 cells - an immortalized cell culture, which is a combination of lymphatic and blood vascular endothelial cells [22]. HMEC-1A cells were maintained in MCDB 131 medium (Sigma-Aldrich), supplemented with 20mM HEPES, 1 $\mathrm{ug} / \mathrm{ml}$ hydrocortisone, $10 \mathrm{ng} / \mathrm{ml}$ EGF and 10\% fetal bovine serum (FBS).

SV-LEC cells, a stable mouse lymphatic endothelial cell line, was isolated from mesenteric adventitial tissue and shown to express specific lymphatic markers Prox-1, LYVE-1 and VEGFR-3 [23]. SV-LEC cells were cultured in DMEM/F12 medium supplemented with 10\% FBS.

HNSCC cell line SCC40 (tongue cancer) was kindly provided by Dr. Susanne Gollin and PCI-15a (pyriform sinus cancer) was provided by Dr. Theresa L. Whiteside (both from the University of Pittsburgh Graduate School of Public Health). FaDu cells, established from hypopharyngeal SCC, were procured from ATCC. SCC40, PCI-15a and $\mathrm{FaDu}$ cultures were maintained in MEM media supplemented with $10 \%$ FBS and non-essential amino acids. $2 \times 10^{5}$ OSC-19 cells, a gift from Dr. Eben L. Rosenthal (University of Alabama at Birmingham), were cultured in DMEM/F12 medium supplemented with $10 \%$ FBS.

\section{Cell Proliferation Assay}

The effects of rapamycin (LC Laboratories, Woburn, MA) on proliferation of SV-LEC or HMEC-1A cells were determined by plating exponentially growing cells in 96-well plates $(2,000$ per well) with $200 \mu \mathrm{l}$ of medium. The cells were incubated at $37^{\circ} \mathrm{C}$ for 3.5 hours for adherence and then treated with vehicle (DMSO) or various concentrations of rapamycin $(1-1000 \mathrm{ng} / \mathrm{ml})$ for time points ranging from 0 to $72 \mathrm{~h}$. Cell proliferation was measured using a modified MTT (3-(4-5-dimethylthiazol-2-yl)-5-(3-carboxymethoxyphenyl)-2(4-sulfophenyl)-2H-tetrazolium salt/phenazine methosulfate) system according to the manufacturer's instructions (CellTiter 96 AQueous cell proliferation assay; Promega Corp., Madison, WI).

\section{Detection of apoptosis in lymphatic endothelial cells by DAPI staining}

SV-LEC (10,000 cells) or HMEC-1A (20,000 cells) were seeded on $12 \mathrm{~mm}$ circular glass cover slips in 24-well plates and allowed to attach for $4 \mathrm{~h}$. Cells were then treated with $100 \mathrm{ng} / \mathrm{ml}$ of rapamycin or vehicle control (DMSO) for $72 \mathrm{~h}$, washed with phosphate-buffered saline (PBS) and fixed in cold 2\% paraformaldehyde for 15 min. Cells were then washed with PBS, fixed with cold $70 \%$ ethanol at $-20^{\circ} \mathrm{C}$ for $1 \mathrm{~h}$ and stained with $1 \mathrm{mg} / \mathrm{ml}$ DAPI for $30 \mathrm{~min}$ in the dark. The coverslips were washed $2 \times$ with PBS, and mounted using DAKO fluorescent mounting fluid onto microscope slides. Cells were viewed and counted using a fluorescent Olympus Bx50 microscope using a $40 \times$ objective. The number of total and apoptotic cells were counted at least in four fields of each slide.

\section{Western Blot Analysis}

Soluble proteins were extracted as previously described [24]. $30 \mathrm{ug}$ of protein was loaded per well and the expression of tumor and lymphatic biomarkers evaluated by western blotting using the following antibodies: 4EBP1 (1:300 dilution), phospho-4EBP1 (serine 37/46; 1:300 dilution), total and phospho-S6 ribosomal protein (serine 235/236, 1:100), actin (1:3,000; - all above - Cell Signaling, Beverly, MA). VEGFR-3/Flt-4 antibody was used at a 1:100 dilution (R\&D Systems, Minneapolis, MN). The expression levels of each marker were quantified after normalizing to actin scan density by immunoblotting.

Vascular endothelial growth factor receptor-2 ELISA assay The effects of rapamycin treatment on serum levels of soluble VEGFR-2 in mouse serum samples were determined using a mouse VEGFR-2 ELISA kit (R\&D Systems, Minneapolis, $\mathrm{MN}$ ) according to manufacturer's instructions.

\section{Results}

Anti-lymphatic effects of rapamycin in orthotopic HNSCC model

Anti-lymphatic effects of rapamycin were evaluated in the orthotopic OSCC tongue tumor model (Figure 1). OSC-19 cells injected into tongues of SCID mice formed tumors (Figure 1A) in all mice and yielded a reproducibly high rate of regional metastases by week 3 . Rapamycin significantly inhibited tumor growth as measured by tumor cross-sectional area at the end of experiment. The mean total cross-sectional area was 27.4 \pm $13.4 \mathrm{~mm}^{2}$ in control mice which was decreased to $8.4 \pm$ $6.7 \mathrm{~mm}^{2}$ in rapacymin-treated mice $(\mathrm{p}<0.0001)$.

Rapamycin significantly decreased intratumoral lymphatic vascular density from $9.1 \pm 4.10$ in control mice to $5.8 \pm 1.18$ in rapamycin-treated mice $(\mathrm{p}=0.027)$ as well as the fraction of lymphatic vessels (identified by LYVE-1 staining) invaded by tumor cells in primary OSC-19 tumors obtained from mouse lingual tissue (Figure 1D). The percentage of lymphatic vessels invaded by tumor cells decreased from $62.78 \pm 15.13 \%$ in controls to $40.44 \pm 20.67$ in the rapamycin-treated mice $(\mathrm{p}=0.013)$.

$\mathrm{H} \& \mathrm{E}$ and cytokeratin stained slides of the cervical lymph nodes were analyzed by the study pathologist to 


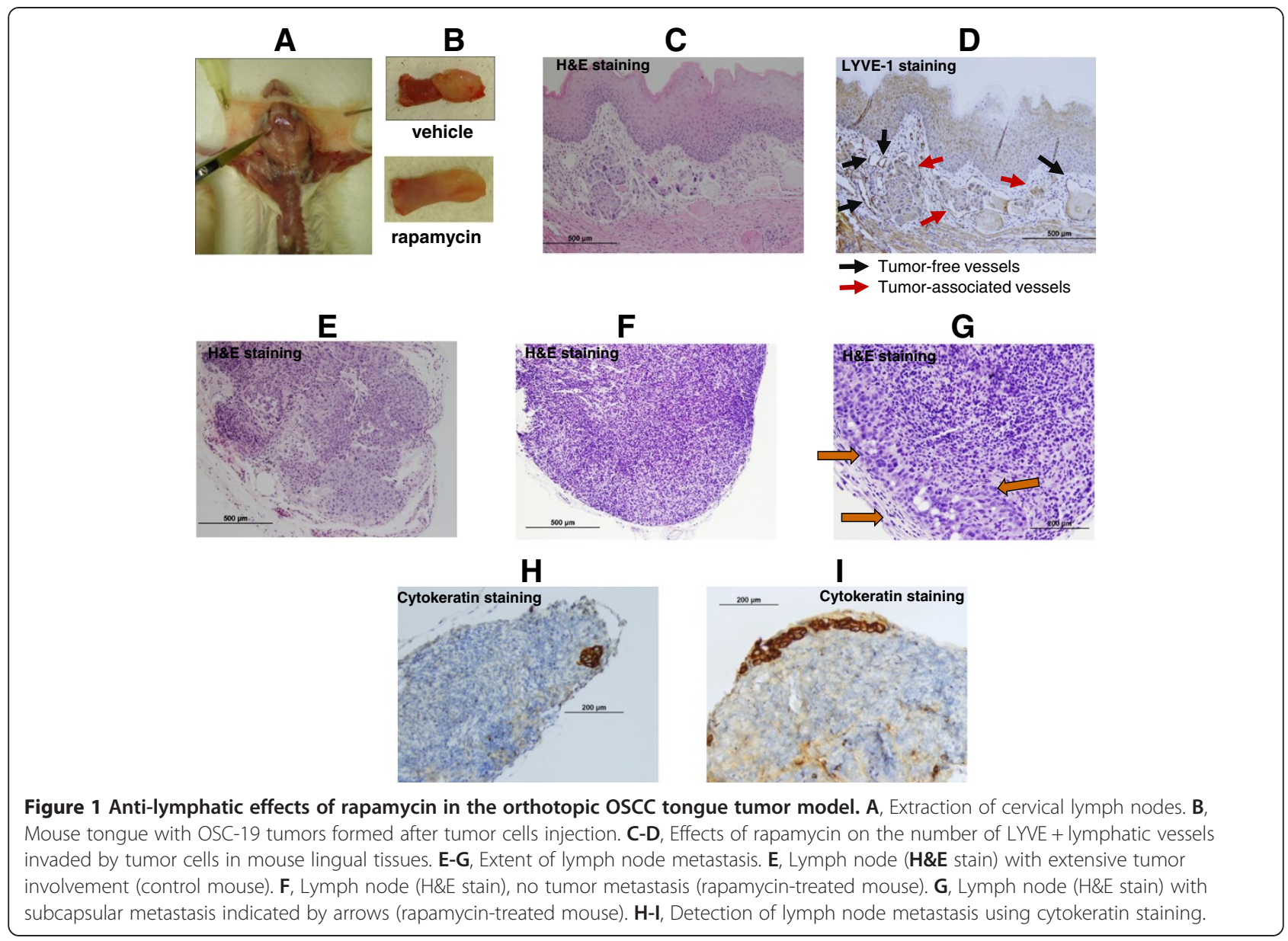

determine the presence of metastases and the extent of spread within the lymph nodes. Following rapamycin treatment we observed a significant decrease in the incidence of cervical lymph node metastases ( $p=0.04$; Fisher exact test of independence). In the control group, 42 of the 66 (63.6\%) lymph nodes evaluated revealed metastatic tumors, while in the rapamycin-treated group only 31 of the 68 (45.6\%) lymph nodes evaluated showed metastasized tumors. This shows that the incidence of cervical lymph node metastases decreased by almost one third after rapamycin treatment. Rapamycin also significantly reduced the extent of tumor spread within the lymph nodes. In the control group 33 of the 42 (78.6\%) lymph nodes with metastatic tumor showed extensive lymph node involvement. By comparison, in the rapamycin-treated group only 8 of the 31 (25.8\%) lymph nodes with metastatic tumor showed extensive lymph node involvement, while $74.2 \%$ of the metastatic lymph nodes had only minimal tumor involvement that was localized to the subcapsular sinuses $(p=0.0001$; Fisher exact test of independence; Figure 1E-I and Table 1).
We also assessed the effects of rapamycin on angiogenesis by quantitating the number of blood microvessels in CD31-stained sections of lingual tumor tissue (Figure 2). At $\times 400$ magnification, the average blood vessel counts per field (mean \pm SD) were: $23.36 \pm 5.56$ blood microvessels in control tumors compared to $14.94 \pm 3.79$ for rapamycintreated tumors $(\mathrm{p}<0.0001$; unpaired $\mathrm{t}$ test with Welch correction). This shows a significant $36 \%$ reduction in blood vessel density following rapamycin treatment.

Table 1 Cervical lymph node metastasis in orthotopic HNSCC mouse model

\begin{tabular}{lll}
\hline & Control & Rapamycin \\
\hline $\begin{array}{l}\text { Number of positive cervical } \\
\text { lymph nodes }\end{array}$ & $42 / 66(63.6 \%)$ & $31 / 68(45.6 \%)^{*}$ \\
$\begin{array}{l}\text { Extent of tumor cell spread } \\
\text { within positive lymph nodes: }\end{array}$ & & \\
$\quad$ Extensive spread & $33 / 42(78.6 \%)$ & $8 / 31(25.8 \%)^{* * * *}$ \\
$\quad$ Subcapsular & $9 / 42(21.4 \%)$ & $23 / 31(74.2 \%)^{* * * *}$ \\
\hline
\end{tabular}

* $-\mathrm{p}<0.05$ (Fisher's test).

**** $-p<0.0001$ (Fisher's test). 


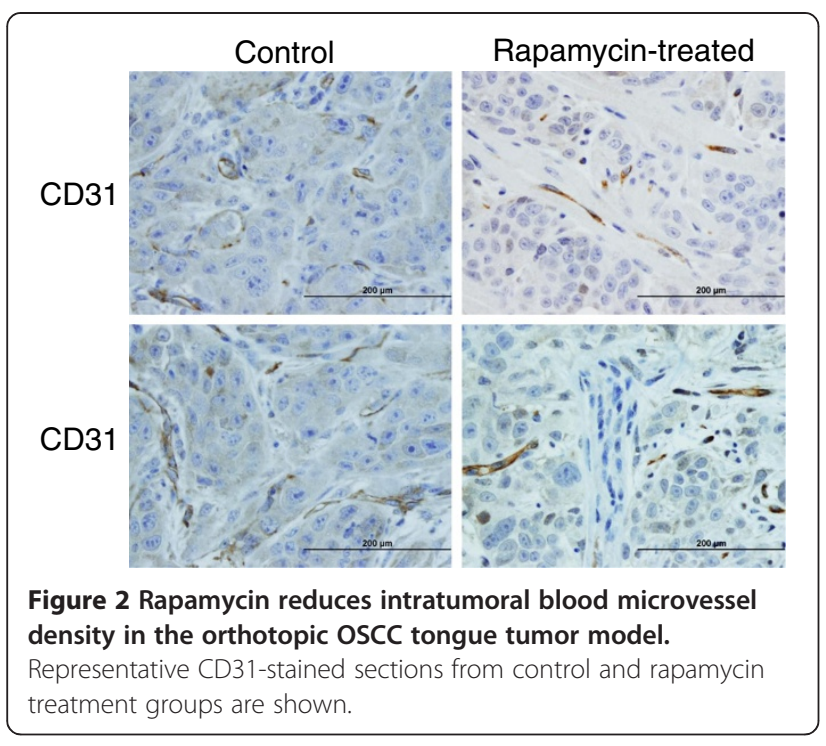

Interestingly, rapamycin treatment significantly increased the level of soluble VEGFR-2 in serum of SCID mice compared to control ( $\mathrm{p}=0.0001$; Figure 3 ).

mTOR inhibition suppresses LEC proliferation and VEGFR3 expression

We found significant inhibition of lymphatic endothelial (LEC) proliferation in both LEC lines at all doses of mTOR inhibitors tested $(1-1000 \mathrm{ng} / \mathrm{ml})$. The growth of SV-LEC and HMVEC-1A cells were inhibited by $>35 \%$ after $72 \mathrm{~h}(\mathrm{P}<0.05)$, indicating potent anti-lymphatic

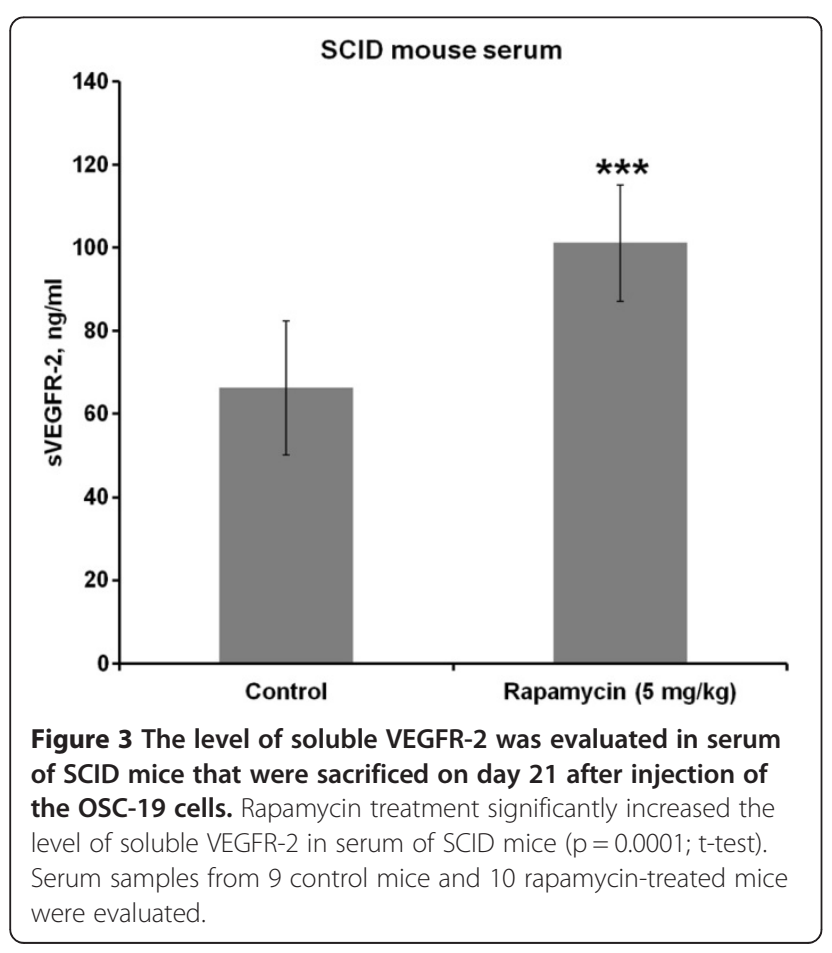

effects of mTOR inhibitors (Figure 4A). Interestingly after $72 \mathrm{~h}$ of rapamycin treatment, we noted a modest but statistically significant increase in a percentage of apoptotic cells in SV-LEC cell (control samples 6.65 $\pm 1.50 \%$; rapamycin-treated samples $10.20 \pm 2.46 \%$; $\mathrm{p}=0.0099$ ). By comparison, there was no significant change in percentage of apoptotic cells for HMEC-1A cell line (control samples $-5.04 \pm 1.39 \%$; rapamycin-treated samples $-6.04 \pm$ $1.99 \% ; \mathrm{p}>0.05)$. These findings indicate a significantly higher inhibition of proliferation of SV-LEC cells than HMEC-1A cells by rapamycin.

The effects of rapamycin on mTOR signaling in LECs were evaluated by Western Blotting analysis. Inhibition of mTOR signaling was demonstrated by a significant decrease in phosphorylation of ribosomal protein S6 at Ser235/Ser236 and by a shift of the phosphorylated isoforms to non-phosphorylated " $\alpha$ " isoform of $4 \mathrm{E}-\mathrm{BP} 1$ (Figure 4B). Interestingly, treatment with rapamycin decreased VEGFR-3 (Flt-4) expression in both LEC and HNSCC cells. We found a significant inhibition of VEGFR-3 expression after rapamycin treatment in both LEC cell lines as well as in two of four HNSCC cell lines tested, namely SCC40 and PCI-15a (Figure 5). Expression of the lymphangiogenic growth factor receptor VEGFR-3 in LEC cells, in SCC40 and PCI-15a HNSCC cells, was decreased by more than $30 \%$ after rapamycin treatment compared to vehicle-treated control (Figure 5B; $P<0.05$; paired two-tailed t-test). Similarly in our animal experiments we observed a decrease in VEGFR-3 expression in lingual tumor tissue from $0.65 \pm 0.99$ in control group to $0.36 \pm 0.25$ in rapamycin-treated group. However due to high variability results were not significant $(\mathrm{p}=0.177)$.

\section{Discussion}

Dissemination of tumor cells to regional lymph nodes via the lymphatic system represents the first step in HNSCC metastasis and is the most important poor prognostic factor for disease recurrence. Tumor-associated lymphangiogenesis plays an active role in metastatic disease spread by providing escape routes for cancer cells and is supported by significant correlation between intratumoral lymphatic vessel density and lymph node metastasis $[25,26]$. HNSCC are highly vascular tumors with remarkable expansion of both blood and lymphatic vascular networks in head and neck area. In our previous study we showed an equally high density of blood and lymphatic vessels in HNSCC patients, underscoring the fact that HNSCC is not only highly angiogenic, but also highly lymphangiogenic [20]. Accumulating evidence now supports rapalogues potent activity against tumor blood vasculature and we have shown that mTOR inhibitors have potent anti-angiogenic effects in HNSCC. Temsirolimus (CCI-779) significantly suppressed angiogenesis in HNSCC xenografts, decreasing intra-tumoral 

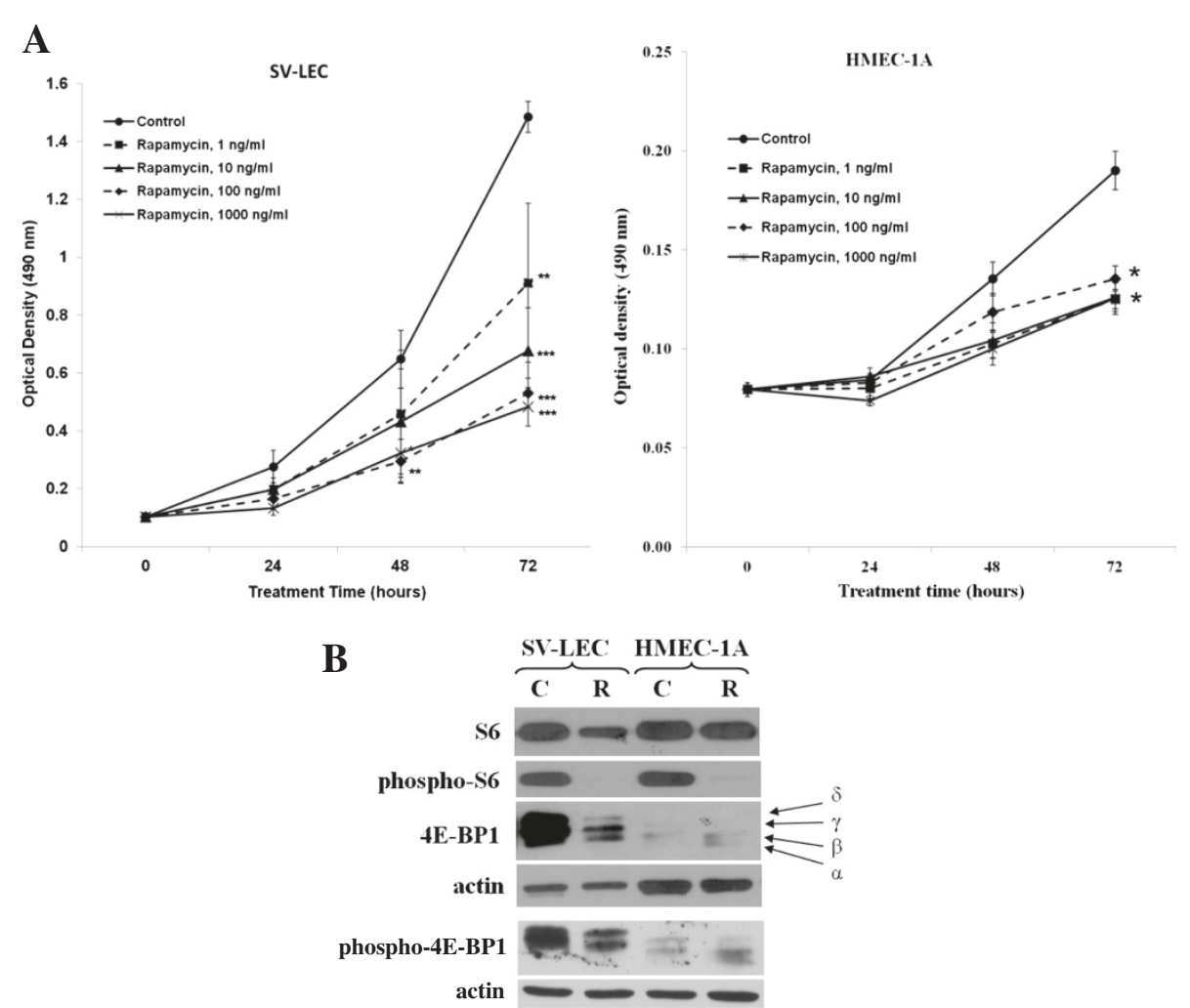

Figure 4 Effects of rapamycin on growth of lymphatic endothelial cells. A, Growth-inhibitory effects of various concentrations of rapamycin $(1-1000 \mathrm{ng} / \mathrm{ml})$ on SV-LEC and HMEC-1A cells. Optical density results are presented as means \pm SD of 3 independent experiments. (* $-p<0.05 \mathrm{vs}$. control;:** $-p<0.01$ vs. control; one-way ANOVA with Tukey's multiple comparison post-hoc test). B, Western blot analysis showing an inhibition of the mTOR signaling pathway by rapamycin (100 ng/ml, 72h) in SV-LEC and HMEC-1A cells. C - Control; R - Rapamycin (100 ng/ml, $72 \mathrm{~h})$.
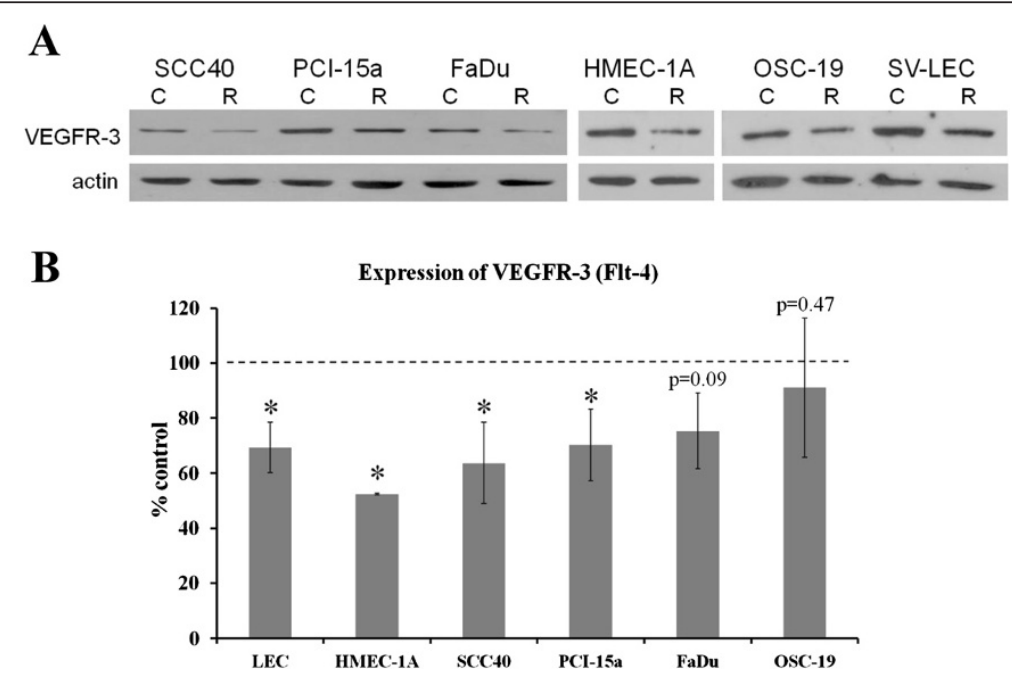

Figure 5 Effects of rapamycin on VEGFR-3 expression. A, Western blot analysis of VEGFR-3/Flt-4 expression in LECS and HNSCC cells after rapamycin treatment (100 ng/ml, 72h). B, Expression of pro-lymphangiogenic VEGFR-3 compared to control in the cell lines tested. The intensities of the VEGFR-3 bands were quantified at least in six independent sets of samples and statistical significance was determined using the paired two-tailed t-test. 
microvessel density by $42 \%(\mathrm{P}<0.001)$ [27]. Similarly in our current study we found a significant $36 \%$ inhibition of blood microvessel density by rapamycin in the HNSCC orthotopic tumor model as well. Several studies show rapamycin also exerts anti-lymphangiogenic effects in vitro [28], blocks in vivo lymphangiogenesis in pancreatic cancer [29], and reduces regenerative lymphangiogenesis in a skin flap model [28]. Together these findings underscore the importance of mTOR-targeted therapy in inhibiting both tumor angio- and lymphangiogenesis. Unlike blood vessel angiogenesis, rapalogues effects on tumor-associated lymphangiogenesis are not well understood, but could provide critical additional target for mTOR inhibitors in the treatment of HNSCC. Recently, in the study by Gutkind et al we demonstrated anti-lymphatic properties of rapalogues in an orthotopic model of HNSCC generated by injection of UMSCC2 cells into the tongue of SCID/NOD mice [20]. In this study we obtained further evidence for the antilymphatic properties of mTOR inhibitors employing OSC-19 orthotopic model of HNSCC and investigated the mechanisms of rapalogues anti-lymphatic effects using in vitro and in vivo models.

Treatment of SCID mice with $5 \mathrm{mg} / \mathrm{kg}$ of rapamycin for 16 days significantly lowered lymphatic microvessel density and significantly reduced lymphovascular invasion and decreased the incidence of cervical lymph node metastasis compared to vehicle-treated controls. Furthermore, rapamycin significantly suppressed the extent of metastatic tumor cell spread within the lymph nodes. Most tumor-positive lymph nodes in the control group (78\%) demonstrated complete replacement of the normal lymph node architecture with tumor cells. Conversely, the majority $(74 \%)$ of positive cervical lymph nodes extracted from rapamycin-treated mice demonstrated only minimal tumor cell spread, with only few metastatic tumor cells localized to subcapsular sinuses, an early stage of cervical lymphatic metastasis known as 'micrometastasis'. This suggests that rapamycin can delay lymphatogenous metastatic spread in head and neck cancer, potentially impeding extracapsular extension of squamous cell carcinoma nodal metastases, a significant poor prognostic factor for decreased patient survival [30].

The results obtained in the animal experiment employing an orthotopic murine model of HNSCC were further supported by in vitro study findings. The LEC proliferation assay showed that mouse and human lymphatic endothelial cells are highly sensitive to mTOR inhibitors, which decreases LEC proliferation by $>35 \%$ in $72 \mathrm{~h}$ of treatment. Interestingly we observed a moderate, but significant increase in apoptotic cell death after rapamycin treatment for a faster proliferating SV-LEC cell line, but not for HMEC-1A cell line, which showed only a minimal increase in the number of apoptotic cells.
Potent anti-lymphatic effects of the rapalogues have now been associated with inhibition of mTOR signaling.

Not only angiogenesis, but lymphangiogenesis too plays an important role in promoting tumor growth and metastasis. The lymphatic system is a main conduit for initial metastasis for many types of solid tumors, including head and neck cancer. VEGF-C and VEGFR-3 are not only expressed by lymphatic EC, but also by a variety of HNSCC cell lines, including the HNSCC cell lines used in this study (SCC40, FaDu, PCI-15a, OSC-19) (Figure 5A). The VEGF-C/VEGFR-3 axis plays an important role in cancer progression through several cellular pathways [26]. Activation of the VEGF-C/VEGFR-3 axis in lymphatic ECs promotes lymph node metastasis, while binding of VEGF-C to VEGFR-3 creates a positivefeedback 'autocrine loop' which further enhances VEGF-C release, to dramatically stimulate cancer cell proliferation as well as lymphangiogenesis [26]. In our study we found that rapamycin strongly suppressed VEGFR-3 expression in both human and mouse lymphatic EC (Figure 5B). Rapalogues also significantly inhibited VEGFR-3 expression in several HNSCC cell lines. Because rapalogues down-regulate VEGFR-3 expression in lymphatic endothelial cells and some HNSCC cells it suggests mTOR inhibitors can suppress this vicious cycle of autocrine growth stimulation to decrease the number of lymph node metastasis, one of the most important factors contributing to poor head and neck cancer prognosis and survival. Mechanistically, another study coauthored by one of the authors of this paper showed that rapamycin affects VEGFR-3 protein expression in LEC cells by inhibiting protein synthesis and promoting protein degradation of VEGFR-3. Importantly rapamycin did not alter the VEGFR-3 mRNA level [31].

Another important observation from this study was that rapamycin significantly increased the level of soluble VEGFR-2 in serum samples in SCID mice implanted with HNSCC. We also observed a rapamycin-induced upregulation in the level of soluble VEGFR-2 in serum samples of nude mice with FaDu HNSCC xenograft tumors (Ekshyyan O., Moore-Medlin T., Nathan CO; unpublished observation). Recently, a soluble form of VEGFR-2 (sVEGFR-2) that is produced by alternative splicing has been identified as an endogenous selective inhibitor of lymphatic vessel growth [32,33].

In a recent study by Silver et al [33] sVEGFR-2 expression was found to be inversely correlated with lymphatic vessel density in head and neck malignant tumors. Interestingly sVEGFR-2 was not expressed in lymphatic vessels, but its expression was specific to the endothelial cells in blood vessels in both malignant tissue as well as adjacent normal tissues [34]. Furthermore it was demonstrated that gene therapy with a splicing variant esVEGFR-2 that produces soluble VEGFR-2 significantly 
suppresses tumor growth and lymph node metastasis in a mouse mammary cancer model [35].

Because soluble VEGFR-2 binds VEGF-C it may competitively inhibit VEGF-C-induced activation of prolymphangiogenic and angiogenic signaling. sVEGFR-2 release could be used as a potential biomarker of antilymphangiogenic and angiogenic responsiveness in clinical trials of mTOR inhibitors and warrants further investigation.

\section{Conclusions}

Our results demonstrate that mTOR inhibitors potently inhibit lymphatic proliferation by interfering with expression of VEGFR-3, an essential lymphatic growth factor receptor necessary for LEC growth and survival. Furthermore, our data suggest that mTOR inhibitors can suppress autocrine and paracrine growth stimulation of tumor and lymphatic endothelial cells by impairing VEGF-C/VEGFR-3 axis and release of soluble VEGFR-2. In an orthotopic murine model of HNSCC rapamycin significantly suppressed lymphovascular invasion, decreased the incidence of cervical lymph node metastasis and delayed the spread of metastatic tumor cells within the lymph nodes. Our findings therefore suggest that mTOR inhibitors can effectively control lymphatogeneous metastasis, the primary predictor of poor survival in HNSCC.

\section{Competing interest}

The authors declare that they have no conflict of interest.

\section{Authors' contributions}

OE contributed to project design, performed animal experiments, analyzed data, participated in data interpretation, and prepared the manuscript. TNM-M assisted in animal experiments and conducted VEGFR-2 ELISA assays. MCR, KS and MAB participated in animal experiments. XR performed the cell culture experiments and western blot analyses. FA, a study pathologist who was blinded to the study details and sample identification, performed histology evaluations. JSA contributed to project design, participated in data interpretation and edited the manuscript. CON, a project leader, envisioned the study, participated in its design, data interpretation, coordination and final manuscript preparation. All authors read and approved the final manuscript.

\section{Acknowledgements}

The study was supported by grant \# R01CA102363 from the National Cancer Institute to C.O. Nathan. The content is solely the responsibility of the authors and does not necessarily represent the official views of the National Cancer Institute or the National Institutes of Health.

\section{Author details}

${ }^{1}$ Department of Otolaryngology/Head and Neck Surgery, Louisiana State University Health Sciences Center, Shreveport, LA, USA. ${ }^{2}$ Feist-Weiller Cancer Center, LSUHSC, Shreveport, LA, USA. ${ }^{3}$ Department of Pathology, LSUHSC, Shreveport, LA, USA. ${ }^{4}$ Department of Cellular and Molecular Physiology, LSUHSC, Shreveport, LA, USA.

Received: 7 April 2013 Accepted: 20 June 2013

Published: 1 July 2013

\section{References}

1. Ries LAG, Young JL, Keel GE, Eisner MP, Lin YD, Horner M-J: SEER Survival Monograph: Cancer Survival Among Adults: U.S. SEER Program, 1988-2001, Patient and Tumor Characteristics. Bethesda, MD: National Cancer Institute, SEER Program, NIH Pub. No. 07-6215; 2007.

2. Sugiura $T$, Inoue $Y$, Matsuki $R$, Ishii $K$, Takahashi M, Abe M, Shirasuna K: VEGF-C and VEGF-D expression is correlated with lymphatic vessel density and lymph node metastasis in oral squamous cell carcinoma: Implications for use as a prognostic marker. Int J Oncol 2009,34:673-680.

3. Warburton G, Nikitakis NG, Roberson P, Marinos NJ, Wu T, Sauk JJ Jr, Ord RA, Wahl SM: Histopathological and lymphangiogenic parameters in relation to lymph node metastasis in early stage oral squamous cell carcinoma. J Oral Maxillofac Surg 2007, 65:475-484.

4. Cooper JS, Pajak TF, Forastiere AA, Jacobs J, Campbell BH, Saxman SB, Kish JA, Kim HE, Cmelak AJ, Rotman M, Machtay M, Ensley JF, Chao KS, Schultz CJ, Lee N, KK F, Radiation Therapy Oncology Group 9501/Intergroup: Postoperative concurrent radiotherapy and chemotherapy for high-risk squamous-cell carcinoma of the head and neck. N Engl J Med 2004, 350:1937-1944.

5. De Carvalho MB: Quantitative analysis of the extent of extracapsular invasion and its prognostic significance: a prospective study of 170 cases of carcinoma of the larynx and hypopharynx. Head Neck 1998, 20:16-21.

6. Vaidya AM, Petruzzelli GJ, Clark J, Emami B: Patterns of spread in recurrent head and neck squamous cell carcinoma. Otolaryngol Head Neck Surg 2001, 125:393-396.

7. Laplante M, Sabatini DM: mTOR signaling at a glance. J of Cell Science 2009, 122:3589-3590.

8. Molinolo A, Amornphimoltham P, Squarize C, Castilho R, Patel V, Gutkind J: Dysregulated molecular networks in head and neck carcinogenesis. Oral Oncol 2009, 45:324-334.

9. Molinolo A, Hewitt $S$, Amornphimoltham P, Keelawat $S$, Rangdaeng $S$, García AM, Raimondi A, Jufe R, Itoiz M, Gao Y, Saranath D, Kaleebi G, Yoo G, Leak L, Myers E, Shintani S, Wong D, Massey H, Yeudall W, Lonardo F, Ensley J, Gutkind J: Dissecting the Akt/mammalian target of rapamycin signaling network: emerging results from the head and neck cancer tissue array initiative. Clin Can Res 2007, 13:4964-4973.

10. Huang S, Houghton P: Inhibitors of mammalian target of rapamycin as novel antitumor agents: from bench to clinic. Curr Opin Investig Drugs 2002, 3:295-304

11. Yu K, Toral-Barza L, Discafani C, Zhang WG, Skotnicki J, Frost P, Gibbons JJ: mTOR, a novel target in breast cancer: the effect of CCl-779, an mTOR inhibitor, in preclinical models of breast cancer. Endocr Relat Cancer 2001, 8:249-258.

12. Rosenwald I, Kaspar R, Rousseau D, Gehrke L: Eukaryotic Translation Initiation Factor 4E Regulates Expression of Cyclin D1 at Transcriptional and Post-transcriptional Levels. J Biol Chem 1995, 270:21176-21180.

13. Shantz $L$, Pegg A: Overproduction of ornithine decarboxylase caused by relief of translational repression is associated with neoplastic transformation. Cancer Res 1994, 54:2313-2316.

14. DeBenedetti A, Joshi B, Graff J, Zimmer S: CHO cells transformed by the translation factor elF4E display increased c-Myc expression but require overexpression of Max for tumorigenicity. Mol Cell Differ 1994, 2:347-371.

15. Lane HA, Wood JM, McSheehy PM, Allegrini PR, Boulay A, Brueggen J, Littlewood-Evans A, Maira SM, Martiny-Baron G, Schnell CR, Sini P, O'Reilly T: mTOR inhibitor RAD001 (everolimus) has antiangiogenic/vascular properties distinct from a VEGFR tyrosine kinase inhibitor. Clin Can Res 2009, 15:1612-1622.

16. Faivre S, Kroemer G, Raymond E: Current development of mTOR inhibitors as anticancer agents. Nat Rev Drug Discov 2006, 5:671-688

17. Morath C, Arns W, Schwenger V, Mehrabi A, Fonouni H, Schmidt J, Zeier M: Sirolimus in renal transplantation. Nephrol Dial Transplant 2007, 22:viii61-viii65.

18. O'Donnell A, Faivre S, Burris HA 3rd, Rea D, Papadimitrakopoulou V, Shand N, Lane HA, Hazell K, Zoellner U, Kovarik JM, Brock C, Jones S, Raymond E, Judson I: Phase I pharmacokinetic and pharmacodynamic study of the oral mammalian target of rapamycin inhibitor everolimus in patients with advanced solid tumors. J Clin Oncol 2008, 26:1588-1595.

19. Sankhala K, Mita A, Kelly K, Mahalingam D, Giles F, Mita M: The emerging safety profile of mTOR inhibiitors, a novel class of anticancer agents. Target Oncology 2009, 4:135-142.

20. Patel V, Marsh CA, Dorsam RT, Mikelis CM, Masedunskas A, Amornphimoltham P Nathan CO, Singh B, Weigert R, Molinolo AA, Gutkind JS: Decreased lymphangiogenesis and lymph node metastasis by mTOR inhibition in head and neck cancer. Cancer Res 2011, 71:7103-7112. 
21. Wells SR, Jennings MH, Rome C, Hadjivassiliou V, Papas KA, Alexander JS: Alpha-, gamma- and delta-tocopherols reduce inflammatory angiogenesis in human microvascular endothelial cells. J Nutr Biochem 2010, 21:589-597.

22. Ades EW, Candal FJ, Swerlick RA, George VG, Summers S, Bosse DC, Lawley TJ: HMEC-1: establishment of an immortalized human microvascular endothelial cell line. J Invest Dermatol 1992, 99:683-690.

23. Ando T, Jordan $P$, Joh T, Wang $Y$, Jennings $M H$, Houghton J, Alexander JS: Isolation and characterization of a novel mouse lymphatic endothelial cell line: SV-LEC. Lymphat Res Biol 2005, 3:105-115.

24. Nathan CO, Amirghahari N, Abreo F, Rong X, Caldito G, Jones ML, Zhou H, Smith M, Kimberly D, Glass J: Overexpressed elF4E is functionally active in surgical margins of head and neck cancer patients via activation of the Akt/ mammalian target of rapamycin pathway. Clin Cancer Res 2004, 10:5820-5827.

25. Maula SM, Luukkaa M, Grénman R, Jackson D, Jalkanen S, Ristamäki R: Intratumoral lymphatics are essential for the metastatic spread and prognosis in squamous cell carcinomas of the head and neck region. Cancer Res 2003, 63:1920-1926.

26. Su JL, Yen CJ, Chen PS, Chuang SE, Hong CC, Kuo IH, Chen HY, Hung MC, Kuo ML: The role of the VEGF-C/NEGFR-3 axis in cancer progression. Br J Cancer 2007, 96:541-545.

27. Ekshyyan O, Rong Y, Rong X, Pattani K, Abreo F, Caldito G, Chang J, Ampil F, Glass J, Nathan C: Comparison of radiosensitizing effects of the mammalian target of rapamycin inhibitor CCl-779 to cisplatin in experimental models of head and neck squamous cell carcinoma. Mol Cancer Ther 2009, 8:2255-2265.

28. Huber S, Bruns C, Schmid G, Hermann P, Conrad C, Niess H, Huss R, Graeb C, Jauch K, Heeschen C, Guba M: Inhibition of the mammalian target of rapamycin impedes lymphangiogenesis. Kidney Int 2007, 71:771-777.

29. Kobayashi S, Kishimoto T, Kamata S, Otsuka M, Miyazaki M, Ishikura H: Rapamycin, a specific inhibitor of the mammalian target of rapamycin, suppresses lymphangiogenesis and lymphatic metastasis. Cancer Sci 2007 98:726-733.

30. Ghadjar P, Simcock M, Schreiber-Facklam H, Zimmer Y, Gräter R, Evers C, Arnold A, Wilkens L, Aebersold DM: Incidence of small lymph node metastases with evidence of extracapsular extension: clinical implications in patients with head and neck squamous cell carcinoma. Int J Radiat Oncol Biol Phys 2010, 78:1366-1372.

31. Luo Y, Liu L, Rogers D, Su W, Odaka Y, Zhou H, Chen W, Shen T, Alexander $J S$, Huang S: Rapamycin inhibits lymphatic endothelial cell tube formation by downregulating vascular endothelial growth factor receptor 3 protein expression. Neoplasia 2012, 14:228-237.

32. Albuquerque RJ, Hayashi T, Cho WG, Kleinman ME, Dridi S, Takeda A, Baffi JZ, Yamada K, Kaneko H, Green MG, Chappell J, Wilting J, Weich HA, Yamagami S, Amano S, Mizuki N, Alexander JS, Peterson ML, Brekken RA, Hirashima M, Capoor S, Usui T, Ambati BK, Ambati J: Alternatively spliced vascular endothelial growth factor receptor-2 is an essential endogenous inhibitor of lymphatic vessel growth. Nat Med 2009, 15:1023-1030.

33. Pavlakovic H, Becker J, Albuquerque R, Wilting J, Ambati J: Soluble VEGFR-2: an antilymphangiogenic variant of VEGF receptors. Ann N Y Acad Sci 2010, 1207:E7-E15.

34. Silver N, Brill Y, Baffi J, Albuquerque R, Ambati J, Valentino J: Soluble VEGFR2 Expression in Head and Neck Malignant Tumors. Otolaryngol Head Neck Surg 2012, 147:180.

35. Shibata MA, Ambati J, Shibata E, Yoshidome K, Harada-Shiba M: Mammary cancer gene therapy targeting lymphangiogenesis: VEGF-C siRNA and soluble VEGF receptor-2, a splicing variant. Med Mol Morphol 2012, 45:179-184.

doi:10.1186/1471-2407-13-320

Cite this article as: Ekshyyan et al: Anti-lymphangiogenic properties of mTOR inhibitors in head and neck squamous cell carcinoma experimental models. BMC Cancer 2013 13:320.

\section{Submit your next manuscript to BioMed Central and take full advantage of:}

- Convenient online submission

- Thorough peer review

- No space constraints or color figure charges

- Immediate publication on acceptance

- Inclusion in PubMed, CAS, Scopus and Google Scholar

- Research which is freely available for redistribution

Submit your manuscript at www.biomedcentral.com/submit
Ciomed Central 